\title{
The Improvement of Foreign Language Teachers' Affective Variables in Universities for Ethnic Minorities
}

\author{
Kun $\mathrm{Li}^{1}$ \\ ${ }^{1}$ School of Foreign Languages, Inner Mongolia University for the Nationalities, China \\ Correspondence: Kun Li, School of Foreign Languages, Inner Mongolia University for the Nationalities, \\ Tongliao, China. E-mail: likunfsu@163.com
}

Received: August 22, 2012 Accepted: September 7, 2012 Online Published: October 19, 2012

doi:10.5539/elt.v5n12p70 URL: http://dx.doi.org/10.5539/elt.v5n12p70

This paper is included in the research "The research on the training methods and systems of foreign language teachers' professional practice ability in universities for ethnic minorities" supported by Inner Mongolia Autonomous Region, China, No. NM-201108.

\begin{abstract}
This paper states the current situation of foreign language teachers' affective variables in universities for ethnic minorities when teaching a foreign language. It emphasizes the urgent need of improvement of affective variables in such universities based on relevant research results and an interview performed in a university for ethnic minorities. Its purpose is to arouse people's attention on teachers' quality development, especially teachers' affective variables. Several methods are mentioned to help teachers build a harmonious atmosphere in the classroom and improve teachers' quality and future language teaching.
\end{abstract}

Keywords: ethnic minority, affective variables, improvement

\section{Introduction}

The research of foreign language teachers' education and development forms its shape in the last eighties internationally, and in the nineties, it attracts attention from scholars and researchers in China (Zhou, 2008: 40). In education, cognition and affection are two basic factors. Affective variables are also called affective intelligence. Affection is an attitude experience of people that reflects whether objective substance satisfies people's need. Teachers' affective variables are the organic composition of teacher qualities and the major motivation of teachers' personality features (Hong, 2010: 126). American humanism psychologist Rogers believes that people's cognitive activities are often accompanied by certain affective variables. When affective variables are held back and even killed, people's potential of self-creation cannot be developed and realized (Xiang, 2003: 24). Positive affective variables can improve learning efficiency successfully.

In recent years, teachers' qualities are paid much more attention than that in previous years. The aim of education is to promote people's all-around development. But people's focus is still on some cognitive variables. Affective variables haven't received much attention as it should do. In fact, active affective variables of teachers are the key factors of successful language teaching and should be regarded as a very necessary element of teachers' development. Teachers can change students' learning attitude, improve students' motivation and reduce students' anxiety. Teachers with favorable affective variables can promote the development of students' active affective variables, help students overcome passive affective variables, avoid emotional illiteracy, and this will surely have optimistic effect on the learning outcome.

\section{The Importance of Affective Variables in Teachers' Quality Development}

Affective variables arouse people's attention centuries ago. The Western harmonious education originated from the ancient Greek period. Socrates, Aristotle, and Plato constructed ancient Greek Athenian ideological systems of education. That is harmonious development of education both in body and in mind. Aristotle believes that the development of the children's body and mind was in the order of the body, effect and intellect. Education, there, must adhere to the patterns to make children develop physically and mentally. He also points out that education without effect cannot make the body strong and intellect cannot find the firm base in the heart and soul (DOU, 2009:4). 
Wen and Ren (2011) points out that in the entire teaching process, recognition activity and affection activities are interweaving together. In language teaching and learning, teachers and students are not only educating, learning and developing intelligence, but also are communicating their affections. Teachers' affective variables will influence students' affective variables directly in class. Thus influence students' learning results. Students show different affective variables to all the learning activities, courses and teachers. Those who show active affections love to communicate with teachers and be active in class; those who show passive affections are not cooperative in class, thus for most of the time, a favorable result can not be expected. So to create a harmonious learning atmosphere is vital to students, and this relies on teachers' affective variables sometimes.

In the New Course Standard (2001) issued by Ministry of Education in China, affective variables are treated as an important variable in education. It states that affective variables are vital factors that influence students' study and development. Some research, for example, Zhou and He (2005) point out that in the interview teachers are aware of the importance of affective variables in language classroom, but in reality they seldom use affections in class or even don't exactly know what to do.

Song (2009) points out that nowadays in universities young teachers are the main groups who are teaching on the platform. They are energetic, but their teaching methods are not perfect, and they need to improve themselves from all aspects. In the conclusion part of Song's paper, he mentions that the basic teacher quality includes the health of psychology, the knowledge of education and psychology, and the ability to communicate with students.

Teaching activity is an interactive and cooperative practice based on equal teacher and student relationship. In language learning classes, teachers should create suitable and happy atmosphere, build relaxed and harmonious teacher and student relationship and let affective variables work properly. Affective variables can enforce students' memorization. Memory is one of the most important factors for language learning. Words, phrases, grammar and other language points all need memorizing. Active affective variables can make the memorizing activity happy and relaxed, thus enforce the memorizing effect; Passive affective variables may make the process boring and hard, thus the effect cannot be satisfying.

There are some misunderstandings for affective variables. Some teachers think that affective variables can only function in the harmonious relationship between teachers and students. And a good teacher and student relationship can improve students' interest. But some teachers don't be aware of the function of affective variables in students' cognition process. According to the psychological research, the most fascinating function of affective variables is the organizing or collapsing function to person's cognition activity. Affective variables are the conditions and guarantee for efficient cognition activity, and will influence the result of cognition activity (Zhou and He, 2005).

The functions of affective variables in English teaching and learning are discussed in detail in some studies. For example, Ouyang and $\mathrm{Wu}(2010)$ state the functions of affective variables from five aspects. Affective variables can help students strengthen the memory of learning content; affective variables can help students stimulate their motivation for learning; affective variables can push students be actively involved in learning; affective variables can regulate students' learning activities; and affective variables can improve students' acceptance ability.

\section{The Current Situation in Universities for Ethnic Minorities}

In some universities for ethnic minorities, students' language abilities are of different levels. Some students of ethnic minorities learn Chinese as a second language in their senior middle school, and learn English as the third language in universities. Thus they will meet some difficulties in learning English because teachers speak English and Chinese in class, and they have difficulty in understanding teachers' language. Sometimes they cannot or even misunderstand teachers' language. The language teachers in such universities are of different nationalities. For example, in the university where the interview is conducted, the teachers are mainly Han and Mongolian. Usually some Mongolian teachers will be assigned to teach students in Mongolian class. But this is not always the case. There are many courses for English majors and it cannot be sure that the courses will be taught by Mongolian teachers. In many cases, teachers of Han nationality will teach a Mongolian class. Even when it is the Mongolian teacher who teaches the Mongolian class, problems will arise because the textbooks are written in English or Chinese. So teachers can only teach in English or Chinese.

Other reasons will be students' anxiety and time limit, etc. Mongolian students usually are shier than other students because many of them came from pastoral areas and they didn't communicate with so many people and lived in the city before. When they come into university, they need more time to adapt the new environment. In the pastoral areas, most of the time they speak Mongolian and Chinese is only a language learnt from senior middle school. They usually don't speak Chinese. In university, they often communicate with their classmates in Mongolian, and in other situations they will speak Chinese. This will not be helpful for their language learning 
because teachers will speak in English or Chinese. When teachers want to explain something difficult to understand, they will do it in Chinese. If the students cannot understand Chinese well, they will not understand what the teachers are saying. At the same time, they are shy and if they cannot understand they usually don't ask the teachers to explain in detail or ask the teachers "why". Sometimes in class students will choose to sit at the back of the classroom, and when it is their turn to answer the questions, they will stand up and lower their head without saying a word. If things go on like this, students will lose interest and motivation to learn and some of them even give up learning.

Teachers also worry about students' learning and try every teaching method now and then in order to motivate students' learning interest. They choose text and exercise carefully and pay attention to the changes in students' homework. But language learning is a complex process. In the teaching process, teachers should pay attention to their affective variables at the same time, and create a harmonious learning atmosphere for students. Students show different affective variables in class. Some of them are keen on courses and activities at school, some are indifferent to study, some are bored and even hate learning.

The affective variables in class can affect students' after- class learning activities directly. If in class teachers cannot motivate students to learn, then after class students will also lose interest in the subject. They will feel that every aspect of the subject is boring and hard. For example, if in a listening class, teachers only play the tape and tell students the answers, students will feel the material is too hard or listening is too hard. After class they may have no courage or motivation to listen any material.

This research interviews 40 English majors in the same Mongolian class. The main questions are:

1. Are you interested in all your English courses?

2. What factors will influence your interest on the class?

3. Do you think the teachers' affections can influence your study?

4. What affective variables of teachers will have an influence on you?

5. Could you give some examples?

In answering the questions, the students mentioned that classroom atmosphere and teachers' attitude influence much on the effect of a class and the interest of students.

In the interview, most students mention that they like a favorable teaching and learning atmosphere, anxiety and a serious teacher's face will reduce their learning interest. 38 out of 40 students say "yes" to the first question. They say they choose the major because they like English and want to learn the courses well in order to have a better job in the future. Only two of them say that they are not interested in language learning, but they are still trying their best to learn all the courses well. When mentioning the factors that influence the study, students say teachers' affective variables will influence much on their interest. When a teacher shows affection, energy, care and patience in class, students' interest will be aroused and they won't feel anxious or depressed. But if a teacher comes into the classroom with a serious face and don't want to communicate with students, students' confidence will be affected and a relaxed classroom atmosphere cannot be expected. Nearly 90 percent of the students say teachers' affective variables can affect their language study. A smile and a moderate feedback will encourage them to try harder next time. If teachers show poor affective variables in class, it may lead to students' fully losing interest of the subject and even have a negative feeling about language learning. Some students mention that they need a kind of safety in class and this influences much on their learning. The affective variables students mention include smile, care, encouragement, mild feedback, patience, and help.

This research also interviews four teachers who are teaching Mongolian classes. They say they try to create a happy atmosphere in class and be kind to students. In language teaching, they try their best to teach students, give them confidence and communicate with them, but as for the concrete ways of affective variables, they admit that they seldom think about them and just think about the ways of teaching their lessons well.

\section{The Need of Improvement of Affective Variables}

Teaching activity is an interactive and cooperative practice between teachers and students based on equal relationship. The affective variables that influence language learning include two parts. The first part is learners' individual factors, and they are anxiety, inhibition, self-esteem and motivation; the second part is the affective variables between learners or between learners and teachers, including empathy and classroom transactions (Xiang, 2003: 23). Positive affective variables can help students build up active attitude towards language learning. Attitude is vital for the successful outcome of everything. Active attitude can guarantee an active learning process. Gardner (1982) points out that if students have a positive attitude towards the target language, 
they are willing to accept the language input; on the contrary, if students have a negative attitude towards the target language, then they are likely to refuse or avoid the activities about the target language.

Anxiety is regarded as the most important affective variable in foreign language learning (Krashen, 1982). Anxiety makes learners scared and nervous, consume learners' energy and attention, and these will influence much on their learning results. Anxiety is students' restlessness and being afraid of making mistakes in studies. It influences students' learning greatly and even leads to the giving up of learning a language. Teachers should create relaxed, free and happy atmosphere for students, arouse students' interest, motivate students' activity, explain language and culture knowledge, organize class activities, offer instruction, help and feedback, etc. The following methods are helpful in successful language classroom:

1) A harmonious learning atmosphere is needed. Harmony is not only suitable for the development of the society and a country, but also for the learning inside and outside the classroom. Teachers should pay attention to their own affective variables and this is vital in creating a harmonious class atmosphere. Teachers' smile will give confidence and warmth to students. Teachers should equip themselves with excellent affections, and this will make the knowledge and information colorful and acceptable to students. Teachers are not only students' teachers, but also their friends. Knowing this will help teachers and students create active classroom atmosphere and organize smooth class teaching activities, thus the teaching task can be finished successfully. Teachers are like actors sometimes. No matter you are happy or not outside the classroom, when you enter the classroom, you must behave happily. A depressed teacher with a long face cannot create a successful teaching and learning atmosphere for students no matter how knowledgeable the teacher is.

2) Use the materials and books creatively. In order to reduce students' anxiety, teachers should choose materials carefully and don't always emphasize the rate of progress and the amount of new knowledge. The materials should be suitable for the students' present learning level. Teachers should realize that they are mostly beginners of English. The material that is natural and interesting can create real experience for students. Beginners and those who don't know much about the language can build up confidence and interest to learn. The material that is bored or specialized will sometimes cause distraction. In order to arouse students' interest, teachers can introduce some relevant culture information, including eating, music, sports, building, people's ideas and ways of doing things, etc. Teachers can combine the language points and interesting information together to present to students fresh knowledge.

3) Communicate with students, and treat each student differently. For students who are extrovert, teachers should give them chances to behave themselves; for those who are introvert, teachers should encourage them fully and praise them often. Pay attention to individual differences. The students in a class of ethnic minorities are of different levels. Some of them begin to learn English in senior middle school; some of them begin to learn English in university. That is to say, they are not all zero-beginners. It is teachers' task to know this and find a balance in class. If teachers teach in a slow speed, some students will not be satisfied because they think the class in not challenging. But if teachers teach in a fast speed, some students will fall behind and even lose interest. Thus the teaching activity will become a failure. So teachers are facing a tough situation. They can try to design different tasks in class for students of different levels. Those who know more than others can receive difficult assignments and those who are beginners can receive easier assignments. Little by little, teachers can balance this according to students' learning progress.

4) Use appropriate and impressive language in class. If teachers want their students to be equipped with happy and active affective variables, they themselves must show eager feeling to teach and this can be seen as the guarantee of successful teaching. In this way teachers can shorten the distance with students. Pay attention to the ways of feedback. Don't hurt students' self-respect, and try to help them correct and avoid the same mistakes. Everyone wants to be praised and approved. Teachers should first praise the good side of students' answers to keep students in high learning spirit. A successful learning practice will give students more confidence and courage to go further. When students make mistakes, teachers should try to ask students themselves to correct first and always act as a friend who is willing to help. Don't use sharp language to point out students' mistakes or give them corrections. Sometimes the endurance of students' mistakes can improve students' confidence. In a classroom where teachers and students are like friends, students can relax and their anxiety is reduced. At the same time, if teachers use mild verbal language and proper body language, students' confidence will be improved much. Teachers' verbal language should be accurate, brief, instructive and clear. In a language classroom, students pay much attention about their teachers' language use. They will notice if teachers' language is beautiful, proper and correct. This will influence their respect to teachers and influence their affective variables indirectly. Body language is another essential element in a language class. Rich and proper body language will ease the anxiety and nervousness of students. 
In language teaching for ethnic minorities, teachers should alter their common teaching method and find the methods that are suitable for their students. When teachers are teaching classes of ethnic minorities, they should be aware of their roles and pay more attention to students' affection, helping them overcome anxiety or shyness.

Use the attractiveness of language. Language is the purpose and also the tool in the language classroom. On the one hand, teachers should use their language properly and clearly in order to convey necessary information. On the other hand, teachers should choose mild and beautiful instructive and feedback language in order to help build up students' confidence and desire to learn. Teachers' active and optimistic language can arouse students' interest and lead students into the learning state naturally.

5) Put the minority language into good use. Teachers can utilize the students' mother tongue in class. For example, in a Mongolian class, no matter the teachers are Han or Mongolian, they can explain the language information by using students' mother tongue. For teachers who cannot speak Mongolian, they can learn some characters of Mongolian, for example, the structure, order of words, and the common phrases. In explain the target language, teachers can compare the words or structures with some of the Mongolian words or uses. This will give students a deep expression. And at the same time, teachers can find some reasons of students' mistakes because they will be closed related with the influence of their mother tongue.

6) Teachers should pay attention to their own personality, knowledge and skills. Teachers' personality influences much on students and the outcome of a class. Whatever every teacher's personality is, on the whole, teachers should always be energetic, kind, careful and willing to help. Teachers' personality not only influences students' learning, but also students' personality to some extent.

Teachers' rich knowledge about language is the guarantee of the building of positive affective variables. Only if teachers themselves have rich knowledge about language, students can have a kind of belief or respect about their teacher, then they are more likely to study hard. At the same time, knowledge about psychology and education is also necessary in the setting up of affective variables. Appropriate knowledge about education and psychology is included in teachers' basic training courses. This kind of knowledge can help know the characteristics and psychology of students, create a happy teaching and learning atmosphere and ensure the success of a class.

7) The idea of humanism should be introduced into language learning classrooms. Usually people only pay attention to the intelligence development of students and neglect their feelings. In humanism, educators call for the full development of human beings. Humanism can help teachers emphasize the feelings of both teachers and students, help students know self-respect and self-esteem, and find their own potential abilities. A classroom with humanism is warm and harmonious.

8) In teacher development programs, affective variables should be discussed in detail. Usually in teacher training or teacher development programs, some lessons or lectures about teaching methods, teacher qualities and the ways of managing classes will be given to teachers, but the concrete ways of improving teachers' affective variables are seldom mentioned. But most teachers are aware that sometimes although they use the newest teaching methods, put all their enthusiasm in teaching and teach in a classroom with modern teaching devices, students still lack interest in the courses. In this kind of situation, students' affective variables should be noticed. Most teachers know they should pay attention to affective variables, but they lack proper ways to create positive variables and on this aspect they need instructions. Teacher training and development programs are good ways for teachers to enhance their teaching and discuss the current problems. So in this program, lessons and lectures about affective variables should be included.

9) Introduce more cultural background knowledge to arouse students' deeper understanding of language. To know more about English-spoken countries' thinking style, beliefs, customs, arts, religion and life style is helpful in arousing students' interest and motivation of language learning and understanding.

Teachers should help students accept their own limitations, find their own values, set realistic goals and try to realize it, set their own standards and be confident for themselves. Teachers should make the best use of teaching skills and strategy to make students live up to their potentials as much as possible.

\section{Conclusion}

Foreign language learning is a very complex process. In language teaching and learning, teachers and students should follow the objective laws of language and language learning, and the learning process is restricted by subjective and objective factors. How to harmonize teaching and learning, teaching content and teaching method, language elements and culture elements, teaching requirements and practical requirements will influence directly the language learning process and learning results (Chen, 2011: 53). 
Maximize English learning efficiency is the core element in teachers' attention. In recent years, people still pay much attention to recognition research, leaving affective variables not much touched. In fact, teachers and students' cognitive and affective variables are interwoven together and play equal roles in teaching and learning activities.

Affective variables are complex matters in fact. It needs to be perfect in the future teaching process. Affective variables can hinder or accelerate the acquisition of language learning. Teachers should improve their affective variables and play their part well in language teaching. For students, teachers are their affective educator. In language class, teachers' affections will influence students' affections directly. Students' affection on study is a vital element in learning. If they have positive learning affection, they are eager to accept the language input, but if they have negative attitude, they will refuse or avoid the relevant language activities. Different learning results rely on different attitudes, different motivations and different involvements. Motivation is the most crucial factor in language learning. An active motivation can make a hard and boring task into a happy journey. Teachers should regard themselves as an artist of teaching, not just a tool or media of teaching.

\section{References}

Chen, X. Y. (2011). Paying Attention to Emotional and Cultural Factors in Second Language Teaching. Journal of Research on Education for Ethnic Minorities, 2, 53-56.

DOU, L. N. (2009). The Affective Factors and Methods of Senior Middle School Learning-disabled Students. Master's thesis.

Edwords, F. (1989). What is humanism? Amherst, NY: American Humanist Association. Retrieved from http://www.jcn.com/humanism.html

Gardner, R. C. (1982). Language attitudes and language learning. In Bouchard Ryan, E., \& Giles, H. (eds), Attitudes Towards Language Variation. Edward Arnold.

Hong, H. L. (2012). A consideration on the requirement of English teachers' professional development from the imperfection of multi-level college English teaching. Journal of Nanchang college of education, 12, 125-127.

Krashen, S. D. (1982). Principles and Practice in Second Language Acquisition. New York: Pergamon Press Ltd.

Ouyang, H., \& Wu, J. F. (2010). Research on affective variables in college English teaching. Creation of Science and Education, 9, 15, 18.

Song, H. (2009). The current situation of college foreign language teachers and the construction of the professional development. Educational research and experiment, 7, 96-98.

Wen, Q. F., \& Ren, Q. M. (2011). Tertiary English teacher professional development with an interactive model. Foreign Language Education in China, 2, 22-24.

Xiang, M. Y. (2003). Affective variables' influence on college English teaching. Foreign Languages and Their Teaching, 3, 23-26.

Zhou, R., \& He, G. K. (2005). The Current Situation of Middle School Teachers' Affective variables in Teaching. Foreign Language Teaching in Schools (Middle Version), 2, 1-4.

Zhou, Y. (2008). The research of development pattern for college English teachers in China. Foreign language learning and teaching practice, 3, 40-47.

\section{Author}

Kun Li, M.A., lecturer of School of Foreign Languages, Inner Mongolia University for the Nationalities. 